\title{
Development and Validation of an Intelligent Load Control Algorithm
}

\author{
Woohyun Kim and Srinivas Katipamula* \\ Pacific Northwest National Laboratory, Richland, WA 99352 USA
}

4

\begin{abstract}
The renewable generation technologies form a significant (>20\%) fraction of grid capacity, however their generation capabilities remain variable in nature. Therefore, utilities will be forced to maintain a significant standby capacity to mitigate the imbalance between supply and demand. Because more than $75 \%$ of electricity consumption occurs in buildings, building loads can be used to mitigate some of the imbalance. This paper describes the development and validation of an intelligent load control (ILC) algorithm that can be used to manage loads in a building or group of buildings using both quantitative and qualitative criteria. ILC uses an analytic hierarchy process to prioritize the loads for curtailment. The ILC process was developed and tested in a simulation environment to control a group of rooftop units (RTUs) 14 to manage a building's peak demand while still keeping zone temperatures within acceptable deviations.

15 The ILC algorithm can be implemented at a low cost on a supervisory controller without the need for 16 additional sensing. By anticipating future demand, the process can be extended to add advanced control 17 features such as precooling and preheating to alleviate comfort when operation of the RTUs is curtailed to 18 manage the peak demand.
\end{abstract}

19

20 Keywords: Analytic hierarchy process; Load control; Demand response; Duty cycling; Load curtailment.

\section{$21 \quad$ Nomenclature}

$\begin{array}{ll}A & \text { Judgment matrix } \\ A_{\text {normal }} & \text { Normalized criteria judgment matrix } \\ A_{p} & \text { Principal eigenvector } \\ a_{i j} & \text { Entry of criteria judgment matrix } \\ A H P & \text { Analytic Hierarchy Process } \\ B & \text { Normalized alternative decision matrix } \\ B & \text { Entry of alternative decision matrix } \\ C & \text { Decision priority vector } \\ C & \text { Entry of decision priority vector } \\ C R & \text { Consistency Ratio } \\ \text { Cooling } & \text { Cooling mode } \\ C . I & \text { Consistency Index } \\ C_{z, \text { eff }} & \text { Effective zone thermal capacitance } \\ \text { Heating } & \text { Heating mode } \\ n_{\text {rtu }} & \text { Number of times the RTU has been curtailed } \\ P_{\text {rated }} & \text { Rated RTU power consumption }\end{array}$

${ }^{*}$ Corresponding author: Tel.: +1 509372 4281; E-mail: Srinivas.Katipamula@pnnl.gov. 
$P_{\text {peak }} \quad$ Target electric power consumption

Power $_{r t u}$ RTU power consumption

Power $_{b d} \quad$ Whole building electric power consumption

$Q_{b} \quad$ Rate of instantaneous heat gain to the building air

$Q_{c} \quad$ Sensible cooling load

RI Random index of consistency

Room $_{\text {rtu }} \quad$ Room priority

RTUs Rooftop units

$s(t) \quad$ Binary signal

$T \quad$ Fixed-length time period

$T_{c s p} \quad$ Cooling set point temperature

$T_{h s p} \quad$ Heating set point temperature

$T_{\text {zone }} \quad$ Zone temperature

$\Delta T_{\text {zone_csp }} \quad$ Temperature difference between zone and cooling set point

$\Delta T_{\text {zone_hsp }} \quad$ Temperature difference between zone and heating set point

$\Delta T_{\text {zone } \delta} \quad$ Zone temperature difference

$T \quad$ Current time

$t-\delta \quad$ Previous sampling time

$\Delta t \quad$ Sampling period

$V \quad$ Raw summation of alternative judgment matrix

$v_{i} \quad$ Element of raw summation of alternative judgment matrix

$W \quad$ Column summation of criteria judgment matrix

$w_{i} \quad$ Element of column summation of criteria judgment matrix

\section{Subscripts}

\section{I}

$J$

$n$

$m$

$T$

$t-\delta$

24

25 Greek

$\delta$
$\lambda$
$\lambda_{\max }$
$\vec{v}$

Raw element of matrix

Column element of matrix

Raw number of matrix

Column number of matrix

Last reading

Previous reading

\section{Introduction}

27 To mitigate the impacts of climate change, there is a significant impetus to make generation of electricity in the United States cleaner by installing rooftop solar photovoltaic (PV) and utility-scale wind generation systems. Although these renewable generation technologies are cleaner, their electric generation is 
variable in nature. These technologies form a significant $(>20 \%)$ fraction of the grid capacity, so utilities will be forced to maintain a significant standby capacity to mitigate the imbalances between supply and demand. This traditional approach of balancing power is cost-effective when the utilities only had to maintain between $5 \%$ and $10 \%$ of the capacity. An alternate approach to mitigating this imbalance is to manage the load (demand side). Because more than $75 \%$ of electricity consumption occurs in buildings, building loads can be used to mitigate some of the imbalance.

The control of building end-use loads has been shown to provide significant demand relief in response to utility requests [11]. In addition, building loads have been used to limit the electric demand when a demand charge is a significant percentage of the total energy cost or when a building has to maintain a certain level of maximum demand in response to changes in the price of electricity over time. However, an accurate and reliable load control strategy is required to manage peak loads because even one excursion could cause a significant increase in utility bills.

The duty-cycling control strategy has been traditionally used to manage peak demand by controlling the ratio of the on-period to the total cycle time of rooftop units (RTUs) or air-handling units [9]. Two traditional duty-cycling strategies exist for operating building RTUs [14]: 1) a parallel duty-cycling approach, in which all RTUs are cycled ON or OFF at the same time; and 2) a staggered duty-cycling approach, in which the RTU ON and OFF cycles are staggered. For example, in case of the staggered duty-cycling only some (e.g., 1/3 or 2/3) of the RTUs operate at any given time. Although both dutycycling methods provide relief from electric demand, neither dynamically prioritizes the RTUs to be curtailed to manage peak electricity consumption. It is generally difficult to identify the RTUs that can be curtailed without affecting zone comfort, and indiscriminate curtailment of RTUs can lead to comfort issues by negatively affecting the zone temperature and humidity conditions. Therefore, a load control strategy is needed that anticipates the future effects of thermal comfort and peak load relief based on current conditions and past historical data.

This paper describes the development and validation of one such intelligent load control (ILC) algorithm that can be used to manage load while also considering occupant comfort. The ILC can dynamically prioritize the available loads for curtailment using both quantitative (deviation of zone conditions from set point) and qualitative rules (type of zone) in a building or multiple buildings (a campus). ILC uses the analytic hierarchy process (AHP) to prioritize loads for curtailment.

The AHP is a structured technique for organizing and analyzing complex decisions based on mathematics and psychology [13]. The process can generate a numerical score to establish the prioritization of each alternative being considered based on associated decision criteria. The AHP is applicable when it is difficult to formulate goal or quantitative criteria for evaluation. The AHP also allows for the use of qualitative as well as quantitative criteria to solve complex decision-making problem [3]. It decomposes the problems into a hierarchy of elements influencing a system by incorporating three levels: the objectives, criteria, and alternatives of a decision. The process has the ability prioritize a set of criteria used to rank the alternatives of a decision and distinguish, in general, the more important factors from the less important factors. Pair-wise comparison judgments are made with respect to the attributes of one level of hierarchy given the attribute of the next higher level of hierarchy from the main criteria to the sub-criteria [4]. AHP can also solicit consistent subjective expert judgment by using a consistency test. Triantaphyllou and Stuart [15] applied the AHP method for solving complex multi-criteria decisionmaking problems in a matrix structure.

The AHP method has been used for demand response control in the power sector. Ding et al. [5] proposed a dynamic load-shedding scheme of electric power systems based on the AHP decision-making process. According to Aalami et al. [1], the AHP can be used to deal with multiple market operational problems such as price spikes, insufficient spinning reserve margin, and system security and reliability. Goh and 
Kok [6] discussed the AHP applied to similar dynamic load-shedding operational problems for the electrical power system. They prioritized dynamic loads according to their importance by using criteria determined from previous experiences and case studies.

Only a few studies have been related to use of the AHP in building applications. Yao et al. [16] applied the AHP to integrate the advantages of four forecasting models of cooling loads and improved accuracies. In that case, the AHP was employed to determine the optimal weights of each model. The proposed approach was shown to significantly improve cooling load forecasting by using pair-wise judgments between models with periodically updated weights. The research conducted by Wong and Li [17] proposed a multi-criteria decision-making model using AHP to evaluate the selection of intelligent building (IB) systems. They identified key selection criteria for IB systems based on a survey of IB practitioners. The AHP was applied to prioritize and assign important weights to the perceived criteria in the survey. The results suggest that the IB system was determined by a disparate set of selection criteria that had different weightings. Work efficiency is perceived to be the most important core selection criterion for various IB systems; user comfort, safety, and cost effectiveness are also considered significant. Brian et al. [2] introduced an expert-based demand curtailment allocation approach using the AHP, which allowed an electric utility to prioritize the load curtailment for each of its distribution substations using loading levels, capacity, customer types, and load categories. The AHP was used to model a decision-making process according to opinions from experts and objective parameters. Simulation case studies were performed to show the demand curtailment allocations among different distribution substations.

This paper describes a load control strategy based on a dynamic prioritization of a list of curtailable loads (e.g., RTUs) that is updated frequently. The ILC based on the AHP is evaluated and validated using a simulation model of a small commercial building that employs four RTUs. Simulation studies are performed to demonstrate how the ILC can be implemented to manage peak energy consumption. Simulation results show that ILC is capable of reducing peak demand without significantly reducing occupant comfort. Overall, the ILC allows coordination of the RTU operations and provides more intelligent means of load management than the traditional duty-cycling approach.

\section{Description of the analytic hierarchy process}

The AHP is a structured technique for organizing and analyzing the complex decisions by numerically weighting the relative importance of each individual alternative and their associated criteria with respect to the goal. AHP consists of four steps: 1) pair-wise comparison of selected criteria, 2) formulation of a priority criteria vector, 3) consistency checking, and 4) aggregation of final priorities. Each of these four steps is briefly described in this section followed by a detailed description of an example implementation.

\subsection{Pair-wise comparison of selected criteria}

AHP was developed based on the calculation of eigenvector, $\vec{v}$, between a pair of alternatives under evaluation [12]. The $A(\vec{v})$ can be calculated by multiplying the eigenvalue, $\lambda$, corresponding to $\vec{v}$ as shown in Equation (1).

$$
A(\vec{v})=\lambda \cdot \vec{v}
$$

The $\lambda$ indicates the comparsion rank of criteria, which has ranking values between $1 / 9$ and 9 that are given by the decision makers. The relative importance of the two criteria is measured and evaluated according to a numerical scale from 1 to 9 . Table 1 shows how to translate the decision-maker's qualitative evaluations of the relative importance of the two criteria into numbers. It is also possible to assign intermediate values (e.g., 2, 4, 6, and 8) that do not correspond to a precise interpretation. The 
higher the value, the more important the corresponding criterion is. Pair-wise comparison is conducted to determine qualitatively which criteria are more important and assign to each criterion a qualitative weight. For example, if $\lambda_{a}$ is absolutely more important than $\lambda_{b}$ it is assigned a value of 9 , and $\lambda_{b}$ must be absolutely less important than $\lambda_{a}$ so it is valued at $1 / 9$.

Table 1 Ranking scale for criteria [13]

\begin{tabular}{|c|l|l|}
\hline $\begin{array}{c}\text { Intensity of } \\
\text { importance }\end{array}$ & \multicolumn{1}{c|}{ Definition } & \multicolumn{1}{c|}{ Explanation } \\
\hline 1 & Equal importance & Two criteria contribute equally to the goal. \\
\hline 3 & Somewhat more important & One criterion is slightly more important than the other. \\
\hline 5 & Much more important & One criterion is strongly more important. \\
\hline 7 & Very much more important & One criterion is very strongly more important. \\
\hline 9 & Absolutely more important & One criterion is absolutely more important. \\
\hline $2,4,6,8$ & Intermediate values & These values are used when compromise is needed. \\
\hline
\end{tabular}

\subsection{Formulation of the priority criteria vector}

A judgment matrix $(A)$ is created based on the pair-wise comparison as shown in Equation (2). The judgment matrix allows a decision-maker to identify, analyze, and rate the strength of relationships between a set of information. The matrix, $A$ is a $n \times n$ real matrix, where $n$ is the number of criteria.

$$
A=\left[\begin{array}{ccc}
a_{11} & \cdots & a_{1 n} \\
\vdots & \ddots & \vdots \\
a_{n 1} & \cdots & a_{n n}
\end{array}\right]
$$

Each entry $a_{i j}$ of $A$ is formed by comparing the row element $a_{i}$ with the column element $a_{j}$. Each entry $a_{i j}$ of the matrix represents the importance of the $i^{\text {th }}$ criterion relative to the $j^{\text {th }}$ criterion based on Table 1 . If $a_{i j}>1$, then the $i^{t h}$ criterion is more important than the $j^{\text {th }}$ criterion; if $a_{i j}<1$, then the $i^{\text {th }}$ criterion is less important than the $j^{\text {th }}$ criterion. If two criteria have the same importance, then the entry $a_{i j}$ is 1 . An element $a_{i i}$ is equally important when compared to itself; therefore, the main diagonal must be $a_{i i}=1$ for all $i$. The entries $a_{i j}$ and $a_{j i}$ satisfy Equation (3):

$$
a_{i j} \cdot a_{j i}=1
$$

The matrix, $A$ is normalized by multiplying the inverse of each column summation $(W)$ as shown in Equations (4) and (5). The normalized judgment matrix $\left(A_{\text {normal }}\right)$ identifies the weights of each criterion. After normalizing, the principal eigenvector $\left(A_{p}\right)$ can be calculated by averaging across the rows shown in Equation (6). The $A_{p}$ of the criteria is a ratio of the numerical values of the criteria that indicates an order of importance among the different criteria.

$$
\begin{gathered}
W=\sum_{j=1}^{n} a_{i j}=\left[\begin{array}{lll}
w_{1} & \cdots & w_{n}
\end{array}\right] \\
A_{\text {normal }}=\left[\begin{array}{ccc}
\frac{a_{11}}{w_{1}} & \cdots & \frac{a_{1 n}}{w_{n}} \\
\vdots & \ddots & \vdots \\
\frac{a_{n 1}}{w_{1}} & \cdots & \frac{a_{n n}}{w_{n}}
\end{array}\right]
\end{gathered}
$$




$$
A_{p}=\left[\begin{array}{cc}
\frac{1}{n} \cdot \sum_{j=1}^{n} \frac{a_{1 j}}{w_{1}} \\
\vdots \\
\frac{1}{n} \cdot \sum_{j=1}^{n} \frac{a_{n j}}{w_{n}}
\end{array}\right]
$$

139

\subsection{Consistency checking}

Human comparisons can be inaccurate and lead to inconsistency between pair-wise comparisons. A typical example of inconsistency in a pair-wise comparison is as follows: if criterion A has double the importance of criterion $\mathrm{B}$, and criterion $\mathrm{B}$ has triple the importance of criteria $\mathrm{C}$, then criterion A should have six times the importance of criteria $\mathrm{C}$. However, if criterion $\mathrm{A}$ is determined to have only 4 times the importance of criterion B, this selection will lead to inconsistency. This inconsistency can lead to incorrect decisions. Therefore, Saaty and Vargas [13] created a consistency test that can be performed by measuring the consistency ratio (CR) using the consistency index (CI) as shown in Equation (7). Table 2 shows the random index (RI) of consistency for varying sizes of matrices. This approach estimates CR to evaluate the degree of inconsistency. If the CR of the matrix is less than 0.2 , the pair-wise comparsion is considered consistent. Otherwise, a new comparison matrix needs to be reconstructed for the pair-wise comparisons to meet the desired consistency, thereby leading to optimal decision making.

$$
\mathrm{CR}=\frac{C I}{R I}=\frac{\left(\frac{\left(\lambda_{\max }-n\right)}{(n-1)}\right)}{R I}
$$

where $\lambda_{\max }$ is the maximum eigenvalue of matrix $A$, and $n$ is the matrix size.

Table 2 Random index table [13]

\begin{tabular}{|c|c|c|c|c|c|c|c|c|c|c|}
\hline $\mathrm{N}$ & 1 & 2 & 3 & 4 & 5 & 6 & 7 & 8 & 9 & 10 \\
\hline Random index & 0 & 0 & 0.58 & 0.90 & 1.12 & 1.24 & 1.32 & 1.41 & 1.45 & 1.49 \\
\hline
\end{tabular}

\subsection{Aggregation of final priorities}

The alternative decision matrix, $B$, is an $n \times m$ real matrix, where $n$ is the number of criteria and $m$ is the number of alternatives as shown in Equation (8). The matrix $B$ is normalized by multiplying the inverse of each raw summation of $B$ as shown in Equations (9) and (10).

$$
\begin{gathered}
B=\left[\begin{array}{ccc}
b_{11} & \cdots & b_{1 m} \\
\vdots & \ddots & \vdots \\
b_{n 1} & \cdots & b_{n m}
\end{array}\right] \\
V=\sum_{i=1}^{m} b_{i j}=\left[\begin{array}{c}
v_{1} \\
\vdots \\
v_{n}
\end{array}\right]
\end{gathered}
$$




$$
B_{\text {normal }}=\left[\begin{array}{ccc}
\frac{b_{11}}{v_{1}} & \cdots & \frac{b_{1 m}}{v_{1}} \\
\vdots & \ddots & \vdots \\
\frac{b_{n 1}}{v_{n}} & \cdots & \frac{b_{n m}}{v_{n}}
\end{array}\right]
$$

159

160

161

162

The decision priority vector, $C$, can be calculated by multipling each element of the normalized alternative decision matrix $\left(B_{\text {normal }}\right)$ as shown in Equation (11). Overall, the decision priority represents the ranking of each alternative in achieving the goal.

$$
C=\left(A_{p}\right)^{T} \cdot B_{\text {normal }}=\left[\begin{array}{lll}
\frac{1}{n} \cdot \sum_{j=1}^{n} \frac{a_{1 j}}{w_{1}} & \cdots & \frac{1}{n} \cdot \sum_{j=1}^{n} \frac{a_{n j}}{w_{n}}
\end{array}\right] \cdot\left[\begin{array}{ccc}
\frac{b_{11}}{v_{1}} & \cdots & \frac{b_{1 m}}{v_{1}} \\
\vdots & \ddots & \vdots \\
\frac{b_{n 1}}{v_{1}} & \cdots & \frac{b_{n m}}{v_{n}}
\end{array}\right]=\left[\begin{array}{c}
c_{1} \\
\vdots \\
c_{m}
\end{array}\right]
$$

163

\section{Intelligent load control using AHP}

ILC using AHP can be deployed to manage any homogeneous controllable loads (e.g., a group of RTUs or a group of lighting loads) that have similar inputs and criteria. Hetrogeneous loads (e.g., a mixture of RTUs and lighting loads) can also be prioritized, but they have to be seperated into homogeneous loads and the AHP applied recursively, as described later in the paper.

In this section, an application of the ILC process to manage the peak electricity consumption of a building that has a set of RTUs is explained in detail. In general, the peak demand is defined as the average power consumption during the fixed-length sliding window (e.g., 15-minute sliding window). In many cases, the peak demand usually lasts for a relatively short period; e.g., when all RTUs in a building are ON simultaneously to meet the temperature set point. To illustrate the ILC process Fig. 1 and Fig. 2 show whole building electric power consumption $\left(\right.$ Power $\left._{b d}\right)$, targeted electric power consumption $\left(P_{\text {peak }}\right)$, the zone temperature and zone cooling set point respectively. When Power $_{b d}$ is approaching $P_{\text {peak }}$, the ILC process starts managing the controllable loads. The time between each consecutive reading is called the sampling periods $(\delta)$; this is the period during which the priority list is updated.

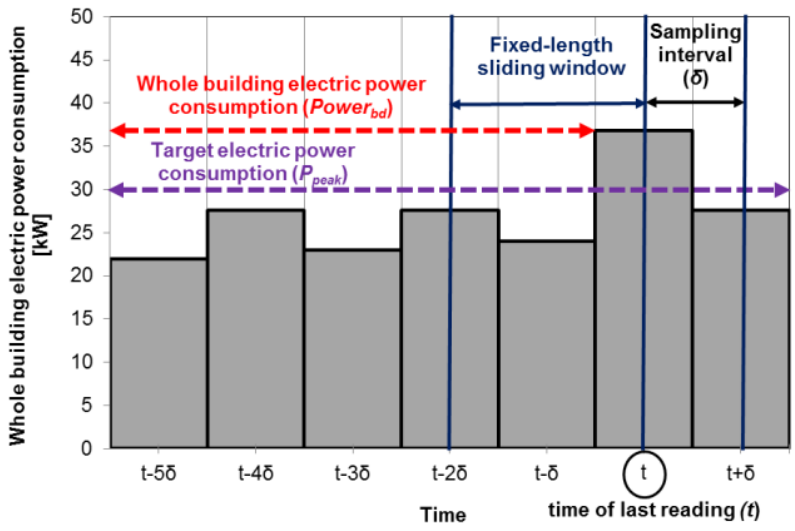

Fig. 1. Example of power consumption during the fixed-length sliding window

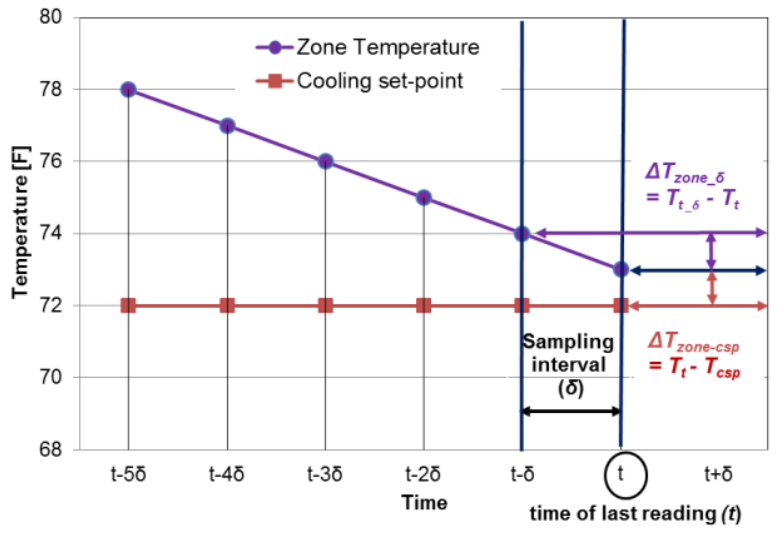

Fig. 2. Example of zone and set point temperature at each sampling period in cooling mode 


\subsection{Prioritization criteria}

180 Any number of relevant criteria can be used to prioritize loads for curtailment to manage electricity consumption. To illustrate how the ILC process can be used to manage the total RTU energy consumption, five pre-determined criteria are used. Additional criteria can be easily added or existing criteria can be modified.

\subsubsection{Criterion 1: RTU power consumption}

185 An estimate or actual measured consumption of the load to be controlled (RTU) is critical to meeting the targeted consumption goal. If measured consumption of the RTU $\left(\right.$ Power $\left._{r t u}\right)$ is not available, an estimate based on the rated power consumption can be used. Assuming that the rated power consumption of the RTU is $P_{\text {rated }}$, then the power consumed by RTU, Power $_{r t u}$, is as shown in Equation (12).

$$
\text { Power }_{\text {rtu }}=\left\{\begin{array}{ll}
P_{\text {rated }} & \text { if } s(t)=1 \\
0 & \text { if } s(t)=0
\end{array}\right\}
$$

where $\mathrm{s}(\mathrm{t})=0$ implies RTU is OFF and $\mathrm{s}(\mathrm{t})=1$ implies RTU is ON.

\subsubsection{Criterion 2: Number of RTU curtailments}

The number of RTU curtailments $\left(n_{r t u}\right)$ represents the total number of curtailments an RTU has experienced during a fixed time period (Time), which is typically 24 hours. For any RTU, if the number of curtailments reaches a certain number $\left(>n_{r t u}\right)$, the corresponding RTU can be excluded from ILC for that day. In general, cycling the RTUs too frequently may result in reduced operating lifespans. This condition may occur when the mass in the zone is small or the RTU is oversized, resulting in a quick change in the zone temperature.

\subsubsection{Criterion 3: Rate of change in zone temperature}

Zone temperature $\left(T_{z o n e}\right)$ represents the temperature condition of the zone served by an RTU. Differential Equations (13) and (14) describe the separate energy balance for the zone cooling load, when considering zone temperature transients [10].

$$
\begin{gathered}
C_{z, e f f} \cdot \frac{\Delta T_{\text {zone__} \delta}}{\Delta t}=Q_{b}-Q_{c} \\
\Delta T_{\text {zone_ } \delta_{-}}=\frac{\left(Q_{b}-Q_{c}\right)}{C_{z, \text { eff }}} \cdot \Delta t
\end{gathered}
$$

where $C_{z, e f f}$ is an effective zone thermal capacitance of the zone air and internal mass, $Q_{c}$ is the sensible cooling load, and $Q_{b}$ is the rate of instantaneous heat gain to the building air. Zone temperature difference $\left(\Delta T_{\text {zone } \_}\right)$is assumed to vary linearly between the previous sampling time $(t-\delta)$ and the time of the last reading $(t)$. If there is no cooling requirement, $\Delta T_{\text {zone } \delta} \delta$ should be negative for a given time period $(\Delta t)$.

Fig. 2 shows the example of $T_{\text {zone }}$ per $\Delta t$ in a cooling mode. $\Delta T_{z_{\text {zone }} \delta}$ can be calculated as shown in Equation (15) for the cooling mode and Equation (16) for the heating mode. When the value of $\Delta T_{z_{\text {zone }} \delta}$ is less than or equal to zero, the cooling requirement is less than zero (e.g., RTU turns off) or $Q_{c}$ is equal to $Q_{b}$. Therefore, $\Delta T_{\text {zone } \delta} \delta$ should be zero. 


$$
\begin{aligned}
& \text { Cooling mode: } \Delta T_{\text {zone }_{\delta}}=\left\{\begin{array}{ll}
\left(T_{\text {zone }, t-\delta}-T_{\text {zone }, t}\right) & \text { if }\left(T_{\text {zone }, t-\delta}-T_{\text {zone }, t}\right)>0 \\
0 & \text { if }\left(T_{\text {zone }, t-\delta}-T_{\text {zone }, t}\right)<0
\end{array}\right\} \\
& \text { Heating mode: } \Delta T_{\text {zone }_{\delta}}=\left\{\begin{array}{ll}
\left(T_{\text {zone }, t}-T_{\text {zone }, t-\delta}\right) & \text { if }\left(T_{\text {zone }, t}-T_{\text {zone }, t-\delta}\right)>0 \\
0 & \text { if }\left(T_{\text {zone }, t}-T_{\text {zone }, t-\delta}\right)<0
\end{array}\right\}
\end{aligned}
$$

\subsubsection{Criterion 4: Deviation of zone temperature from zone set point}

The thermostat for the RTU is a feedback controller. The controller relies on a measured zone temperature $\left(T_{\text {zone }}\right)$, while adjusting the output signals to activate the necessary stages of heating or cooling when the zone is in the occupied mode. In the unoccupied mode, the zone thermostat activates the necessary stages of cooling or heating, along with the RTU ventilation fan, when the zone temperature rises above the setback upper limit value or falls below the setback lower limit value. The cooling set point $\left(T_{c s p}\right)$ and heating set point $\left(T_{h s p}\right)$ represent the zone temperature threshold. The thermostat turns ON the RTU only when the zone temperature is either above the cooling set point or below the heating set point. Once the RTU is turned ON to provide cooling, it remains ON until the zone temperature falls $0.5^{\circ} \mathrm{F}$ below the set point to protect the RTU from short cycling.

Fig. 2 shows an example of temperature difference $\left(\Delta T_{\text {zone-csp }}\right)$ between $T_{z o n e}$ and $T_{c s p}$ in the cooling mode. $\Delta T_{\text {zone-csp }}$ reflects the occupant's comfort status in the zone corresponding to each RTU. The input to the AHP is the inverse value of $\Delta T_{\text {zone-csp }}$ and $\Delta T_{\text {zone-hsp }}$ as shown in Equation (17) for the cooling mode and Equation (18) for the heating mode. When the difference between $T_{z o n e}$ and $T_{c s p}$ (or $\left.T_{h s p}\right)$ is lower than 0.1, $\Delta T_{\text {zone-csp }}\left(\Delta T_{\text {zone-hsp }}\right)$ should be set to 10 .

$$
\begin{aligned}
& \text { Cooling mode: } \Delta T_{\text {zone-csp }}=\left\{\begin{array}{cc}
\frac{1}{\left(T_{\text {zone }}-T_{\text {csp }}\right)} & \text { if }\left(T_{\text {zone }}-T_{c s p}\right)>0.1 \\
10 & \text { if }\left(T_{\text {zone }}-T_{c s p}\right) \leq 0.1
\end{array}\right\} \\
& \text { Heating mode: } \Delta T_{\text {zone-hsp }}=\left\{\begin{array}{ll}
\frac{1}{\left(T_{\text {hsp }}-T_{\text {zone }}\right)} & \text { if }\left(T_{\text {hsp }}-T_{\text {zone }}\right)>0.1 \\
10 & \text { if }\left(T_{h s p}-T_{\text {zone }}\right) \leq 0.1
\end{array}\right\}
\end{aligned}
$$

\subsubsection{Criterion 5: Room/zone type}

Room priority $\left(\right.$ Room $\left._{r t u}\right)$ can be used to prioritize the rooms for curtailment of power consumption. Higher numerical values assigned to a given room is regarded as less important (more likely to be curtailed first) than rooms with lower numerical values. Users would set their own priority depending on the importance of the room (1: most important and 7: less important). Table 3 shows an example of AHP priority based on building room type. The Room $_{r t u}$ weight is zero while heating or cooling operation is OFF. Where an RTU serves multiple spaces of varying importance, the users will need to determine the Room $_{r t u}$ as they see fit.

Table 3 Example of AHP priority based on room type

\begin{tabular}{cccccccc}
\hline & $\begin{array}{c}\text { Director's } \\
\text { office }\end{array}$ & Office & $\begin{array}{c}\text { Vacated } \\
\text { office }\end{array}$ & $\begin{array}{c}\text { Conference } \\
\text { room }\end{array}$ & $\begin{array}{c}\text { Mechanical } \\
\text { room }\end{array}$ & $\begin{array}{c}\text { Computer } \\
\text { lab }\end{array}$ & Kitchen \\
\hline AHP priority & 1 & 3 & 7 & 5 & 7 & 1 & 3 \\
\hline
\end{tabular}


A number of additional parameters, described in the following sections, are needed to prioritize the loads for curtailment.

\subsubsection{Temperature offset value}

If the building electric energy consumption is approaching the targeted peak demand, some or all of the RTUs that are currently running have to be curtailed. In most cases, direct control of the RTUs is not possible; therefore, an alternate approach is used. In the alternative approach, the set points are offset by a fixed value, which will result in the RTU turning OFF. After the demand control event is over or if the next prioritization results in a different set of RTUs on the top, the set points will be restored to normal values.

\subsubsection{Curtailment time period}

The ILC manages the RTU consumption by cycling the units ON or OFF in a building to prevent the peak demand from exceeding the targeted demand. When the demand control event has ended and the set points for curtailed units are restored to normal, most RTUs are likely to be turned ON. This can result in an unwanted peak demand that can be equal to or even higher than the targeted peak demand value. It is important to manage the targeted peak demand at exactly the right level, in order to release the available loads currently under curtailment at appropriate times. Thus, the ILC process has an option to specify the curtailment time period. When a RTU is curtailed, it will remain curtailed for the specified duration.

\subsubsection{Target peak demand}

The target peak demand can be determined by the building operator, which can vary seasonally. Therefore, the target demand can be adjusted seasonally.

\subsubsection{Minimum RTU runtime}

RTU operation is controlled by cycling the RTU compressor "ON" or "OFF." Each RTU has a finite lifespan, which may be shortened; therefore, RTU manufacturers ensure that the compressors are not cycled frequently. In addition to the safety features built into the RTU, the ILC ensures that the compressors are not cycled frequently by using a RTU runtime clock. The 5-minute runtime is used as a default. This often means that the RTU is excluded from any priority decision-making until both internal (RTU timers) and external timer values are met.

\subsubsection{RTU operating mode (heating or cooling)}

The RTU operating mode is the present heating or cooling mode at time $t$ and is used as a reference input to calculate the value of $\Delta T_{\text {zone-csp }}$ or $\Delta T_{\text {zone-hsp }}$ and $\Delta T_{\text {zone_ } \delta}$.

\section{Intelligent load control process}

The primary goal of the ILC process is to prioritize controlable loads (e.g., RTUs) that can be curtailed to keep a building's dynamic electric demand from exceeding the targeted demand chosen by the building/facitliy operations staff. Fig. 3 shows the AHP having three major elements in the decision model: the goal, the criteria, and the alternatives. The AHP comprises relative weights of the decision criteria and the relative priorities of alternatives. The goal of the ILC process is to generate the dynamic load curtailment priority for controlling the building's peak demand to keep from exceeding the target. The intermediate-level consists of five different decision criteria (user selected) as explained below. The lowest level consists of seven different decision alternatives, which are different RTUs that are coordinated to curtail their energy use. Making load curtailment decisions requires comparing alternatives with respect to a set of decision criteria. 


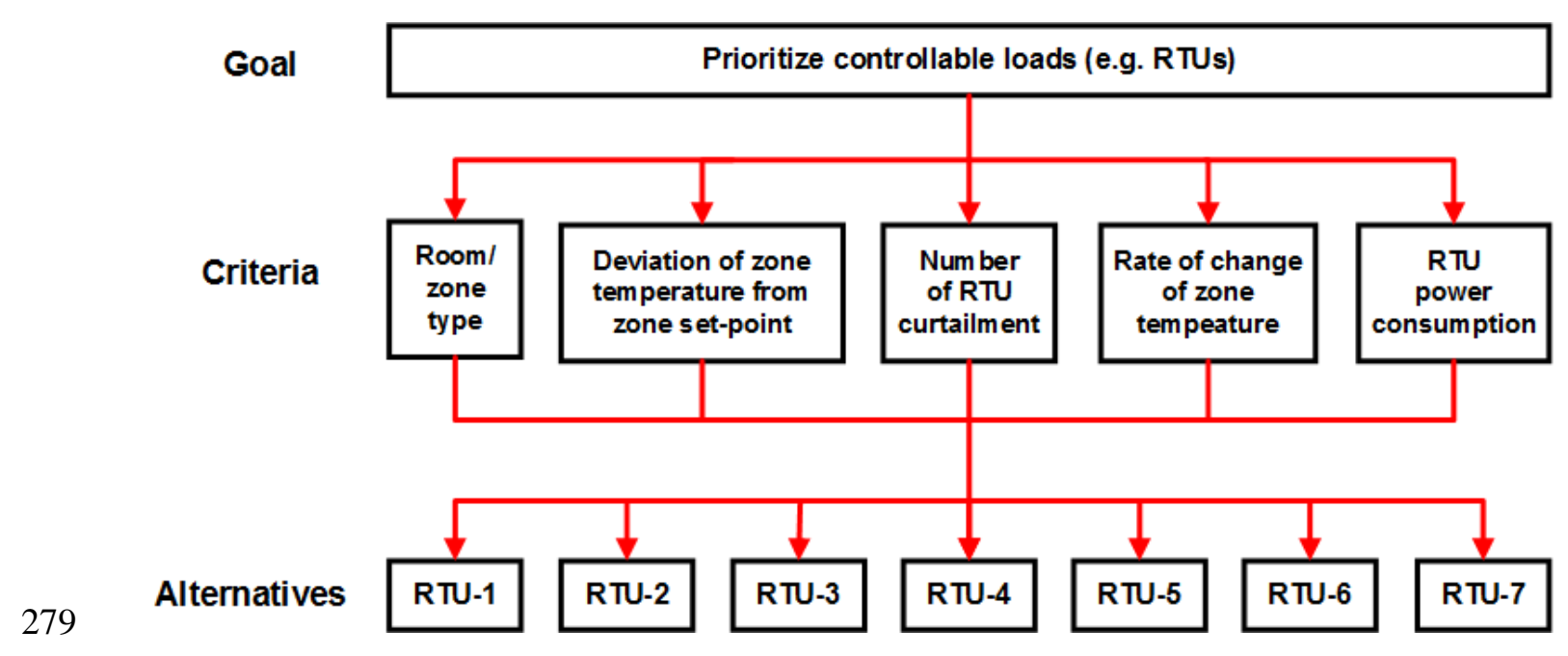

Fig. 3. AHP model for managing building peak demand using RTU loads

\subsection{Evaluation of each criterion}

Table 4 shows the pair-wise comparsion matrix for the ILC process. The pair-wise comparisons are performed to determine the mutual importance (varying degrees of load priority criteria) as described earlier in Table 1. The weight for each evaluation criterion is created according to the pair-wise

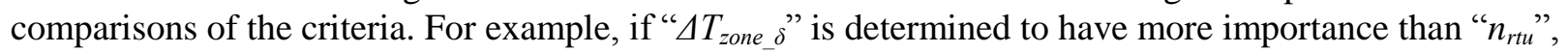
a value of 6 is assigned to this comparison. Thus, the value of " $n_{\text {rtu }}$ " compared to " $\Delta T_{\text {zone } \delta}$ " would be $1 / 6$. Although the table below shows five criteria, additional criteria can be easily added or a criterion can be replaced with another more important one.

Table 4 Pair-wise comparison of ILC decision criteria

\begin{tabular}{|c|c|c|c|c|c|c|c|c|c|c|c|c|c|c|c|c|c|c|}
\hline \multirow[t]{2}{*}{ Criteria } & \multicolumn{2}{|c|}{$\begin{array}{l}\text { Extreme } \\
\text { important }\end{array}$} & \multicolumn{2}{|c|}{$\begin{array}{c}\text { Very } \\
\text { much } \\
\text { important }\end{array}$} & \multicolumn{2}{|c|}{$\begin{array}{c}\text { Much } \\
\text { important }\end{array}$} & \multicolumn{2}{|c|}{$\begin{array}{l}\text { Slightly } \\
\text { important }\end{array}$} & \multirow{2}{*}{$\begin{array}{c}\text { Equal } \\
1\end{array}$} & \multicolumn{2}{|c|}{$\begin{array}{l}\text { Slightly } \\
\text { important }\end{array}$} & \multicolumn{2}{|c|}{$\begin{array}{c}\text { Much } \\
\text { important }\end{array}$} & \multicolumn{2}{|c|}{$\begin{array}{c}\text { Very } \\
\text { much } \\
\text { important }\end{array}$} & \multicolumn{2}{|c|}{$\begin{array}{l}\text { Extreme } \\
\text { important }\end{array}$} & \multirow[t]{2}{*}{ Criteria } \\
\hline & 9 & 8 & 7 & 6 & 5 & 4 & 3 & 2 & & 2 & 3 & 4 & 5 & 6 & 7 & 8 & 9 & \\
\hline$n_{r t u}$ & & & & & & & & & & & & & & & & & & $\Delta T_{\text {zone } \delta}$ \\
\hline$n_{r t u}$ & & & & & & & & & & & & & & & & & & Room $_{\text {rtu }}$ \\
\hline$n_{r t u}$ & & & & & & & & & & & & & & & & & & Power $_{r t u}$ \\
\hline$n_{r t u}$ & & & & & & & & & & & & & & & & & & $\Delta T_{\text {zone-sp }}$ \\
\hline$\Delta T_{\text {zone } \delta}$ & & & & & & & & & & & & & & & & & & Room $_{\text {rtu }}$ \\
\hline$\Delta T_{\text {zone } \delta}$ & & & & & & & & & & & & & & & & & & Power $_{\text {rtu }}$ \\
\hline$\Delta T_{\text {zone } \delta}$ & & & & & & & & & & & & & & & & & & $\Delta T_{\text {zone-sp }}$ \\
\hline Room $_{\text {rtu }}$ & & & & & & & & & & & & & & & & & & Power $_{\text {rtu }}$ \\
\hline Room $_{r t u}$ & & & & & & & & & & & & & & & & & & $\Delta T_{\text {zone-sp }}$ \\
\hline Power $_{r t u}$ & & & & & & & & & & & & & & & & & & $\Delta T_{\text {zone-sp }}$ \\
\hline
\end{tabular}

\subsection{Calculation of criteria priority vector}

Table 5 shows the matrix $A_{\text {normal }}$ and eigenvector $A_{P}$ of the criteria. The $A_{\text {normal }}$ shows the relative weight for each evaluation criterion according to the pair-wise comparisons of the load priority criteria. Because $A$ is normalized by $W$ in Equation (5), the sum of each column in $A_{\text {normal }}$ should be 1 . The $A_{P}$ vector shows the ratios of the numerical values that indicate the strength of each criterion's preferences. The priority vector indicates the rankings among the criteria. In Table 5, the most important criterion for proritorizing the curtailable loads is $\Delta T_{\text {zone_s }}$, followed by $\Delta T_{z o n e \_} \delta$, Power $r$ rtu,$n_{r t u}$, and $R o o m_{r t u}$. The priority vector also shows the relative weights of the criteria. $\Delta T_{\text {zone } \_s p}$ is 1.6 times more important than $\Delta T_{\text {zone } \delta}$. The $C . R$ 
values calculated using Equation (7) is 0.04, which is less than 0.1; therefore, the eigenvector $A_{P}$ of

Table 5 Matrix $A_{\text {normal }}$ and eigenvector $A_{P}$ of criteria

\begin{tabular}{|c|c|c|c|c|c|c|}
\hline & \multicolumn{5}{|c|}{$A_{\text {normal }}$} & \multirow{2}{*}{$A_{P}$} \\
\cline { 2 - 6 } & $n_{\text {rtu }}$ & $T_{\text {zone at t- } \delta}$ & $T_{\text {zone at } t}$ & Room $_{\text {rtu }}$ & Power $_{\text {rtu }}$ & \multirow{2}{*}{0.08} \\
\hline$n_{\text {rtu }}$ & 0.07 & 0.02 & 0.19 & 0.07 & 0.08 & 0.08 \\
\hline$\Delta T_{\text {zone_ } \delta}$ & 0.28 & 0.07 & 0.01 & 0.05 & 0.17 & 0.26 \\
\hline Room $_{\text {rtu }}$ & 0.02 & 0.42 & 0.06 & 0.04 & 0.07 & 0.05 \\
\hline Power $_{\text {rtu }}$ & 0.21 & 0.28 & 0.31 & 0.21 & 0.17 & 0.19 \\
\hline$\Delta T_{\text {zone_sp }}$ & 0.42 & 0.21 & 0.43 & 0.63 & 0.51 & 0.42 \\
\hline
\end{tabular}

302

303

304

305

306

307

Table 6 RTU input data of criteria for matrix B

\begin{tabular}{|c|c|c|c|c|c|c|c|c|}
\hline Criteria & Unit & RTU-1 & RTU-2 & RTU-3 & RTU-4 & RTU-5 & RTU-6 & RTU-7 \\
\hline$n_{\text {rtu }}$ & {$[\mathrm{ea}]$} & 1 & 1 & 1 & 1 & 1 & 1 & 2 \\
\hline$T_{\text {zone at } t-\delta}$ & {$\left[{ }^{\circ} \mathrm{F}\right]$} & 76.17 & 74.85 & 72.71 & 75.59 & 74.53 & 75.01 & 76.17 \\
\hline$T_{\text {zone at } t}$ & {$\left[{ }^{\circ} \mathrm{F}\right]$} & 76.21 & 73.51 & 71.21 & 74.88 & 71.51 & 74.07 & 76.21 \\
\hline Room $_{r t u}$ & {$[-]$} & Office & $\begin{array}{c}\text { Director's } \\
\text { office }\end{array}$ & Kitchen & Office & $\begin{array}{c}\text { Computer } \\
\text { lab }\end{array}$ & $\begin{array}{c}\text { Conference } \\
\text { room }\end{array}$ & Office \\
\hline Power $_{\text {rtu }}$ & {$[\mathrm{kW}]$} & 7.2 & 1.8 & 3.2 & 6.9 & 3.5 & 2 & 7.4 \\
\hline$T_{s p}$ & {$\left[{ }^{\circ} \mathrm{F}\right]$} & 75 & 72 & 71 & 72 & 71 & 73 & 73 \\
\hline
\end{tabular}

Table 7 shows the matrix $B_{\text {normal, }}$ which includes the weight of each criterion associated with each alternative load (RTUs) according to the pair-wise comparisons and the input data. The comparsion reflects the intensity as indicated by the ratios of the numerical values that preserve the strength of alternative preferences.

Table 7 Matrix $B_{\text {normal }}$ of alternative loads (RTUs)

\begin{tabular}{|c|c|c|c|c|c|c|c|}
\hline Criteria & RTU-1 & RTU-2 & RTU-3 & RTU-4 & RTU-5 & RTU-6 & RTU-7 \\
\hline$n_{\text {rtu }}$ & 0.11 & 0.11 & 0.00 & 0.22 & 0.22 & 0.22 & 0.11 \\
\hline$\Delta T_{\text {zone } \delta}$ & 0.00 & 0.18 & 0.20 & 0.09 & 0.40 & 0.13 & 0.00 \\
\hline Room $_{\text {rtu }}$ & 0.16 & 0.05 & 0.16 & 0.16 & 0.05 & 0.26 & 0.16 \\
\hline Power $_{\text {rtu }}$ & 0.23 & 0.06 & 0.10 & 0.22 & 0.11 & 0.06 & 0.23 \\
\hline$\Delta T_{\text {zone } s p}$ & 0.27 & 0.21 & 0.00 & 0.11 & 0.00 & 0.30 & 0.10 \\
\hline
\end{tabular}

\subsection{Calculation of decision priority vector}

The decision priority vector $C$ of alternatives can be calculated by multiplying eigenvector, $A_{p}$, and matrix, $B_{\text {normal }}$, thus determining dynamic prioritization of the loads. As can be seen in Table 8, the ILC process proritizes the RTUs for curtailment (priortiy of 1 implies that it will be curtailed first). Once the loads are prioritized for curtailment, the number of RTUs that need to be curtailed to meet the peak demand can be determined based on their current power consumption. 
Table 8 Decision priority vector $\mathrm{C}$ for load curtailment

\begin{tabular}{|c|c|c|c|c|c|c|c|}
\hline & RTU-1 & RTU-2 & RTU-3 & RTU-4 & RTU-5 & RTU-6 & RTU-7 \\
\hline $\begin{array}{l}\text { Priority } \\
\text { Weight }\end{array}$ & 0.20 & 0.14 & 0.07 & 0.15 & 0.10 & 0.21 & 0.13 \\
\hline Priority & 2 & 3 & 7 & 5 & 4 & 1 & 6 \\
\hline
\end{tabular}

\subsection{Load control based on the decision priority vector $s$}

Table 9 shows the current power consumption of each of the seven RTUs and the total consumption for this example data set is $36.8 \mathrm{~kW}$. Assuming a target demand of $30 \mathrm{~kW}$, curtailing RTU-6 and RTU-1 (based on the decision priority shown in Table 8) will bring the total consumption below $30 \mathrm{~kW}$. The curtailment can be implemented by raising the zone set point from $72^{\circ} \mathrm{F}$ to $76^{\circ} \mathrm{F}$. As the set points are raised, the compressors of the RTUs are turned OFF until the zone temperature exceeds the set point or the event is released, and the compressor has met the minimum OFF time.

Table 9 RTU set point-based decision priority vector and target building demand

\begin{tabular}{|c|c|c|c|c|c|c|c|}
\hline & RTU-1 & RTU-2 & RTU-3 & RTU-4 & RTU-5 & RTU-6 & RTU-7 \\
\hline RTU power $[\mathrm{kW}]$ & 6.8 & 2.8 & 5.4 & 6.8 & 5.4 & 2.8 & 6.8 \\
\hline Tsp $\left[{ }^{\circ} \mathrm{F}\right]$ & 76 & 72 & 72 & 72 & 72 & 76 & 72 \\
\hline
\end{tabular}

\section{Results and discussion}

A small commercial building simulation model was used to evaluate and validate the ILC process. Kim et al. [8] developed a three-zone building for simulating the dynamic indoor environments and building envelopes using a reduced-order coupled computational fluid dynamics model. The simulation model was validated by using measurements from the field site. For detailed description and validation of the simulation model, please refer to Kim et al. [7 and 8]. Table 10 shows the summary of building simulation conditions. A one-month simulation was performed to study the potential for reducing the peak demand using ILC. The peak demand is assumed to be the highest average power consumption measured in a rolling 15-minute period. The weather data from 2014 TMY3 (Typical Meteorological Year) was used for the simulations.

Table 10 Major building simulation parameters

\begin{tabular}{|l|l|}
\hline \multicolumn{1}{|c|}{ Input } & \multicolumn{1}{c|}{ Condition } \\
\hline Simulation time periods & One month from July 15 to August 14 \\
\hline Outdoor air temperature data & TMY3 \\
\hline Building type / location & A restaurant/Philadelphia \\
\hline Building size & $70 \mathrm{ft}$. width $/ 65 \mathrm{ft}$. depth/11 ft. height \\
\hline Building occupancy time & $9: 30$ a.m. to $10: 00 \mathrm{p} . \mathrm{m}$. \\
\hline Normal occupied / unoccupied set points & $71.5 / 75.0^{\circ} \mathrm{F}$ \\
\hline AHP occupied set point & $80.0^{\circ} \mathrm{F}$ \\
\hline Thermostat temperature dead band & $\pm 0.5^{\circ} \mathrm{F}$ \\
\hline RTU compressor minimum run time & 5 minute \\
\hline Thermostat delay time & 5 minute \\
\hline
\end{tabular}

Four RTUs serve the open-spaced (without walled-in spaces) building. The room/zone priority is the same for all RTUs because they serve an open space. RTU-1 and RTU-3 serve the dining area and RTU-2 and RTU-4 serve the wine bar. The supply air fans of all RTUs are ON continuously when the building is occupied. RTU-1 has two refrigerant circuits with a nominal cooling capacity of 15 tons. Each of the two compressors is connected to a separate condenser. The other three RTUs have a 4-ton cooling capacity 
with one refrigerant circuit each. The coefficient of performance (COP) of RTU-1 is approximately 35\% higher than the others. All RTUs are controlled by a thermostat with a fixed occupied set point of $71.5^{\circ} \mathrm{F}$ and a dead band of $\pm 0.5^{\circ} \mathrm{F}$. The second compressor of RTU- 1 turns ON when the space temperature is $1.0^{\circ} \mathrm{F}$ above its cooling set point. To avoid short cycling of the RTU compressors, the RTU is run for some minimum period before it is turned OFF. After a change in thermostat set point, the thermostat typically responds with a time delay. The RTU compressor minimum run time and thermostat delay time are set at 5 minutes each. After the set points are changed, there is a delay before the thermostat applies the change, which is referred to as thermostat delay time.

The zone temperature set point is increased to turn OFF the corresponding RTU that is chosen by the priority order. When the load curtailment ends, the set points are returned to their original values. For RTUs with a single compressor, the set point during curtailment is $75.6^{\circ} \mathrm{F}$. The multi-stage RTUs are considered multiple single-stage RTUs. The RTU-1 is considered as two separate single-stage RTUs. To turn OFF the second compressor of RTU-1, the set point is set to the current zone temperature served by RTU-1. When an RTU is OFF during prioritization, that RTU is excluded from the priority decision. If an RTU is turned OFF by the ILC process and the zone temperature corresponding to that RTU exceeds the 364 new set point, then the RTU is allowed to resume its operation.

Fig. 4 shows how the time period affects peak demand management. The targeted peak demand is set to $30 \mathrm{~kW}$ and it roughly corresponds to $85 \%$ of the base case peak demand. The time period refers to the minimum time the unit remains OFF to meet the target. Three different time periods, 5, 15, and 30 minutes, were considered to evaluate the effect of the time period on peak demand management. When the electric power is higher than $30 \mathrm{~kW}$, the RTUs are curtailed using the priority order to reduce the demand by $6 \mathrm{~kW}$ because the base peak is $36 \mathrm{~kW}$. The ILC process increases the zone set point of the RTUs selected for curtailment, which results in those units turning OFF. The normal zone set points are restored after the time period ends. For example, if the ILC time period is 15 minutes, the curtailed RTU will remain OFF for 15 minutes. However, during this 15-minute period, if the zone set point exceeds the new zone set point, the unit will be released from curtailment and allowed to run. The short time periods (upper right graph in Fig. 4) can lead to more frequent cycling of the RTUs but can result in less discomfort to the occupants. The long time period (lower right graph in Fig. 4) prevents short cycling but may result in more occupant discomfort. 

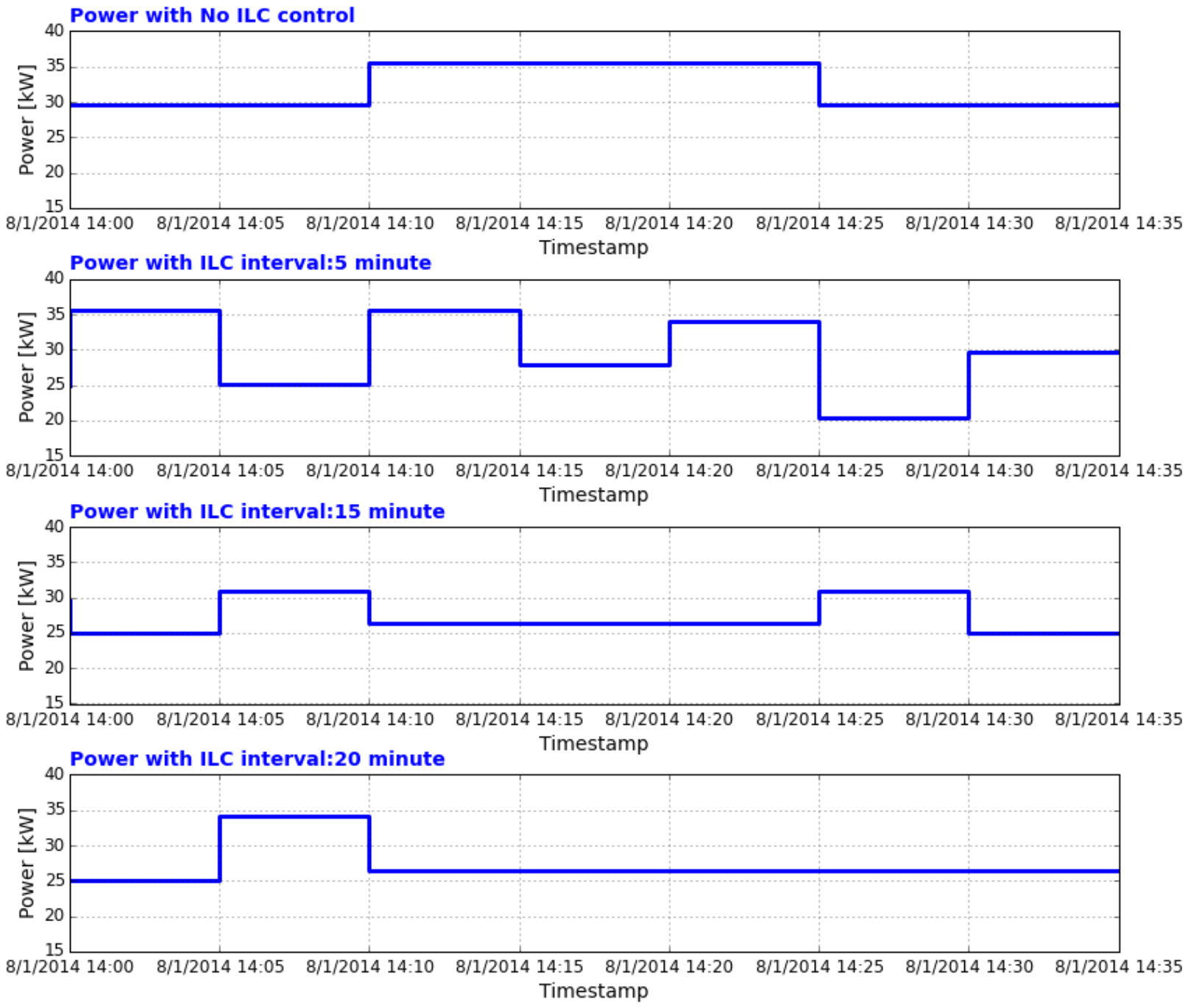

Fig. 4. Electricity consumption profile under different ILC time periods

Weekly electricity consumption profiles under different time periods are shown in Fig. 5. The week between July 25 and August 2 was chosen because it was one of the hottest weeks of the year. The blue line (in Fig. 5) represents the electric consumption profile, the top of the yellow shaded areas represents the peak consumption with conventional operations, and the bottom of yellow shaded area indicates the new demand target with ILC in operation. With conventional control, the peak demand is approximately $36 \mathrm{~kW}$. The goal for the ILC process is to maintain the peak under $30 \mathrm{~kW}$. With the ILC time period of 5 minutes, the peak demand at times is higher than $30 \mathrm{~kW}$. When ILC is operated using 15- and 30-minute time periods, the process is able to achieve the goal at all times. The peak demand is much smoother, with fewer fluctuations, for higher time periods. The ILC operation using 15- and 30-minute time periods can also prevent the "rebound" that occurs during equipment recovery, compared to ILC using 5-minute time periods. 

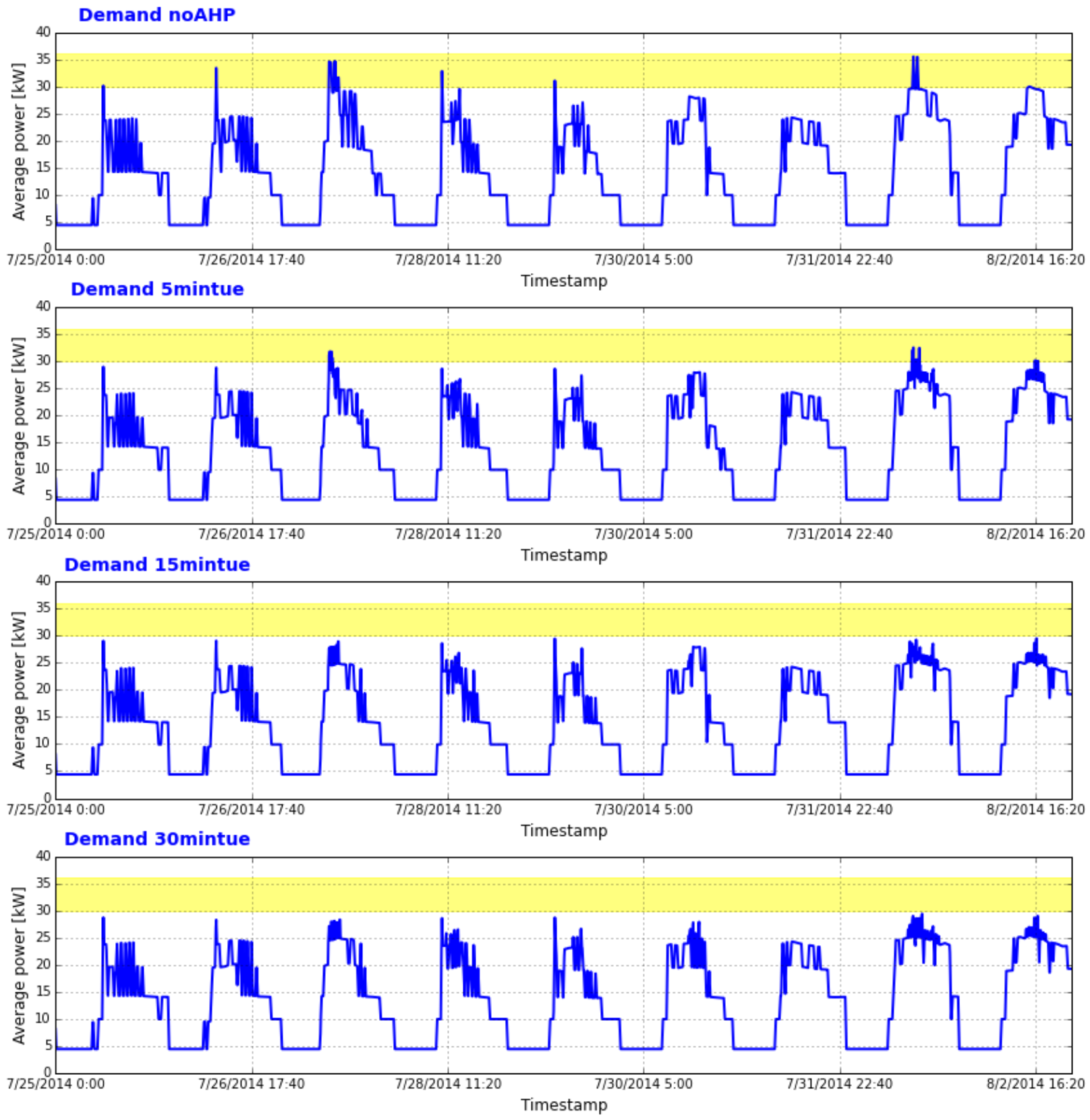

Fig. 5 Weekly electricity consumption profiles under different ILC time periods

Because the zone set points are raised during ILC operation, the zone temperatures will be typically higher than normal in the cooling mode and lower than normal in the heating mode. Fig. 6 shows how ILC affects the zone temperature with the varying ILC time periods. The edges of the yellow shaded area represent the upper and lower bounds of comfort in the cooling mode. The occupied and unoccupied cooling set points are $71.6^{\circ} \mathrm{F}$ (horizontal red line) and $75.6^{\circ} \mathrm{F}$, respectively. The black line represents the unoccupied zone temperature, whereas the occupied zone temperature is marked with a solid color line. When the building is unoccupied, the temperature set point is increased to a higher value leading to an increase in the zone temperature. To manage the peak demand target, the ILC process raises the set point of the RTUs based on the priority list. Although the temperature difference between the conventional 
404

405

406

407

408

409

410

411

(uncontrolled) and ILC approaches increases with the time periods, the zone temperatures for all four RTUs remained below the upper comfort temperature boundary during the occupied period. For example, the deviation of zone temperatures from the normal set point with the ILC time period of 30 minutes is between 2 and $3^{\circ} \mathrm{F}$ higher. The space temperatures show values that drop to as low as $65^{\circ} \mathrm{F}$ during the nighttime. The simulation model was developed based on linearization on the hot summer days.

Therefore, the model could have unrealistic behavior if the system operates too far away from the linearized conditions [7]. Overall, the ILC control using 15- and 30-minute time periods can reduce the peak loads by controlling the RTUs, while still maintaining reasonable thermal comfort.
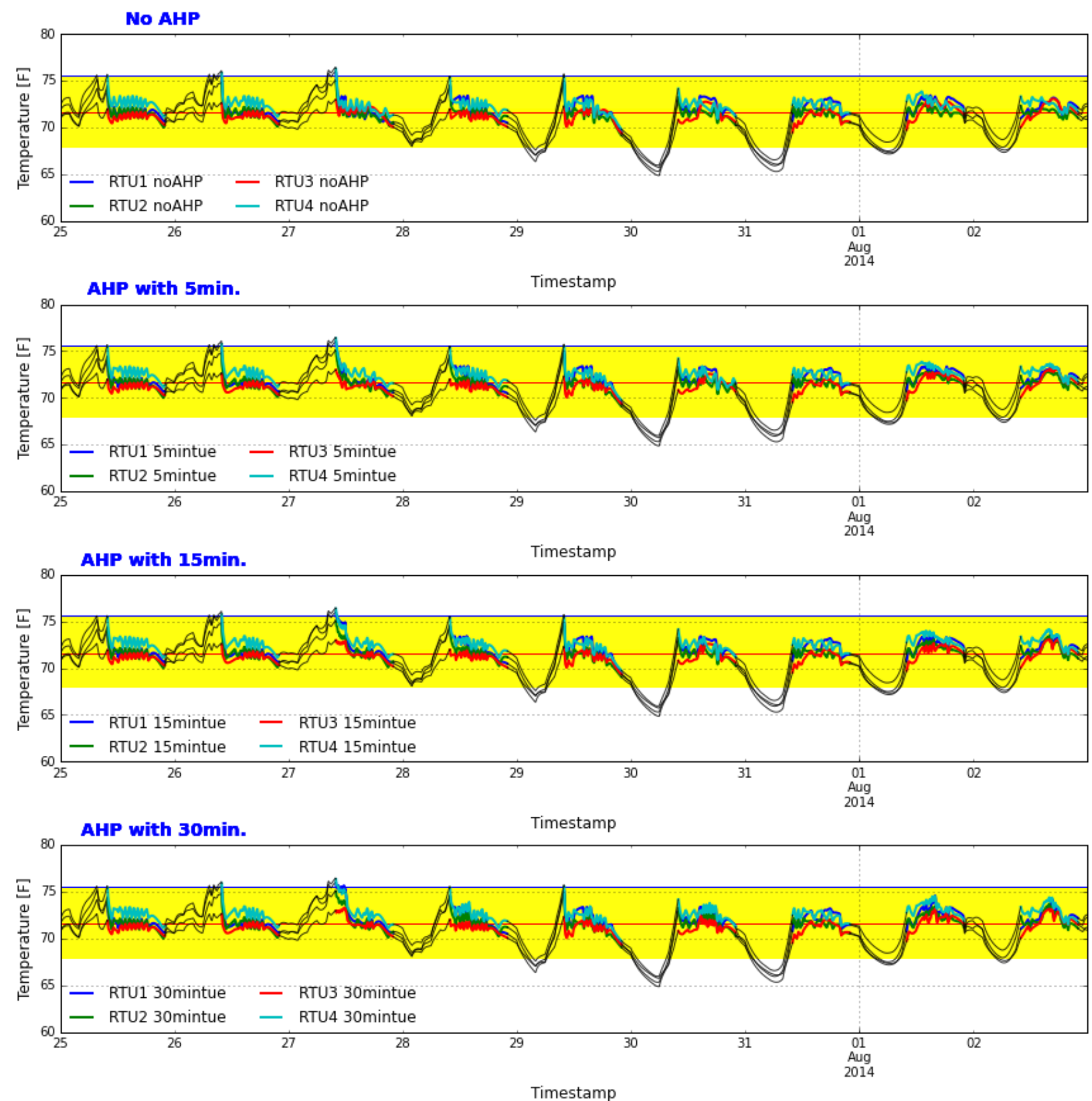

Fig. 6. Zone temperature profiles under different ILC time periods 
Table $\mathbf{1 1}$ shows the maximum and average temperature for each RTU during the occupied time period during a one-month operating period. As seen from the data, the ILC process did not result in a significant zone temperature rise when the units were curtailed to achieve the peak demand goal. For example, the ILC process using a time period of 30 minutes showed an average and maximum temperature rise of $0.4^{\circ} \mathrm{F}$ and $1.9^{\circ} \mathrm{F}$, respectively, compared to the conventional control during the occupied period. Overall, the ILC process using 15- and 30-minute time periods can maintain occupant comfort while successfully limiting peak demand.

Table 11 Comparison of zone temperatures under different ILC time periods

\begin{tabular}{|c|c|c|c|c|c|c|c|c|}
\hline & \multicolumn{3}{|c|}{ Maximum Zone Temperature $\left({ }^{\circ} \mathrm{F}\right)$} & \multicolumn{4}{|c|}{ Average Zone Temperature $\left({ }^{\circ} \mathrm{F}\right)$} \\
\hline \multirow{2}{*}{ Normal } & \multirow{2}{*}{} & \multicolumn{2}{|c|}{ ILC Time Period (minutes) } & \multirow{2}{*}{ Normal } & \multicolumn{2}{|c|}{ ILC Time Period (minutes) } \\
\cline { 3 - 5 } & & 5 & 15 & 30 & & 5 & 15 & 30 \\
\hline RTU1 & 73.5 & 73.6 & 74.7 & 75.5 & 72.6 & 72.6 & 72.6 & 72.8 \\
\hline RTU2 & 72.6 & 72.9 & 73.4 & 74.8 & 71.8 & 72.1 & 72.1 & 72.3 \\
\hline RTU3 & 73.1 & 73.1 & 73.1 & 74.3 & 71.8 & 71.9 & 71.9 & 71.9 \\
\hline RTU4 & 73.8 & 74.0 & 74.5 & 75.9 & 72.7 & 73.0 & 73.3 & 73.4 \\
\hline Average & 73.3 & 73.4 & 73.9 & 75.2 & 72.2 & 72.4 & 72.4 & 72.6 \\
\hline
\end{tabular}

Table 12 shows the RTU ON-OFF cycles and compressor runtimes during a one-month operating period. The results show that RTU-1 with stage 2, RTU-2, and RTU-3 cycled more often to meet the targeted peak demand under the ILC process than under normal control. The number of ON-OFF cycles of RTU-1 with stage 1 and RTU-4 were almost constant regardless of the ILC time period. As the ILC time period decreases, there is an increase in the on/off cycling and a decrease in the running time of the RTUs. For example, the ILC using the 5-minute time period results in $4 \%$ fewer run hours and $27 \%$ more on-off cycling compared to normal control. As the ILC time period increased, the on-off cycling rates were significantly reduced. For instance, the ILC using the 30-minute time period results in almost $6 \%$ fewer run hours and $12 \%$ more on-off cycling compared to normal. The RTU-1 has two refrigerant circuits, which allow modulation of the compressor staging and results in less on-off cycling. The result indicates that the ILC process can provide modest energy savings while managing the peak with a small impact on the thermal comfort. Therefore, the ILC process can provide cost savings derived from both reductions in energy use and peak charges. Overall, the ILC process using the 15- and 30-minute time periods should be considered.

Table 12 RTU on-off cycles and running time under different ILC time periods

\begin{tabular}{|c|c|c|c|c|c|c|c|c|}
\hline & \multicolumn{3}{|c|}{ The Number of On-Off Cycles } & \multicolumn{4}{c|}{ Run Time (hours) } \\
\hline \multirow{2}{*}{ Time period } & \multirow{2}{*}{ Normal } & \multicolumn{2}{|c|}{ ILC Time Period (minutes) } & \multirow{2}{*}{ Normal } & \multicolumn{2}{|c|}{ ILC Time Period (minutes) } \\
\cline { 3 - 5 } & & 5 & 15 & 30 & & 5 & 15 & 30 \\
\hline RTU1-1 & 387 & 381 & 383 & 381 & 243.8 & 248.5 & 249.4 & 250.2 \\
\hline RTU1-2 & 78 & 106 & 114 & 120 & 8.7 & 10.3 & 11.9 & 11.3 \\
\hline RTU2 & 272 & 416 & 324 & 316 & 127.5 & 118.2 & 118.2 & 119.4 \\
\hline RTU3 & 36 & 76 & 88 & 72 & 64.2 & 40.3 & 32.6 & 18.0 \\
\hline RTU4 & 109 & 141 & 125 & 101 & 381.4 & 378.8 & 378.7 & 380.7 \\
\hline Total & 882 & 1120 & 1034 & 990 & 826 & 796 & 791 & 780 \\
\hline Comparisons & Baseline & $27 \% \uparrow$ & $17 \% \uparrow$ & $12 \% \uparrow$ & Baseline & $4 \% \downarrow$ & $4 \% \downarrow$ & $6 \% \downarrow$ \\
\hline
\end{tabular}




\section{Conclusions}

441 The ILC process has been shown to manage peak demand goals while meeting comfort constraints. The ILC process uses the AHP to dynamically prioritize the available controllable loads for curtailment in a building or a group of buildings. The ILC process was tested in a simulation environment to control a group of RTUs to manage a building's peak demand. The test has shown that the peak load can be reduced while still maintaining the zone temperatures within acceptable deviations. The ILC process can be implemented on low-cost hardware (e.g., Beagle Bone, Raspberry Pi, Intel NUC, etc.) on a supervisory controller without the need for additional sensing. By anticipating future demand, the process can be extended to add advanced control features such as precooling and preheating to alleviate comfort when the RTUs are curtailed to manage the peak demand. Although the ILC process described and validated in this paper was highly tailored to work with RTUs, it can be generalized and applied to any controllable loads in a building, such as those of variable air volume boxes and lighting. Furthermore, the ILC process can be extended to manage building loads based on an energy budget instead of peak consumption.

\section{Acknowledgments}

454 The authors acknowledge the Buildings Technologies Office of the U.S. Department of Energy (DOE) 455 Office of Energy Efficiency and Renewable Energy for supporting the research and development effort. 456 The authors would also like to thank Joseph Hagerman, Senior Advisor and Technical Development 457 Manager at DOE for thoughtful comments and insights; and Weimin Wang for the technical review of the 458 report.

\section{References}

460 [1] Aalami, H. A., Moghaddam, M. P., and Yousefi, G. R., 2010, Modeling and prioritizing demand response

[2] Bian, D., Pipattanasomporn, M., and Rahman, S., 2015, A Human Expert-Based Approach to Electric Peak Demand Management, IEEE Trans. Power deliver 30(3), 1119-1127.

[3] Cheng, E. W. L., and Li H., 2002, Construction partnering process and associated critical success factors: quantitative investigation, Journal of Management in Engineering 18(4), 194-202.

[4] Crowe, T. J., and Noble J.S., 1998, Multi-attribute analysis of ISO 9000 registration using AHP, International Journal of Quality and Reliability Management 15(2), 205-22.

[5] Ding, Z., Srivastava, S., and Cartes, D., 2006, Expert system based dynamic load shedding scheme for shipboard power systems. In Industry Applications Conference, Oct. 2006, 41st IAS Annual Meeting Conference Record of the 2006 IEEE, 3(2), 1338-1344.

[6] Goh, H. H. and Kok, B. C., 2010, Application of Analytic Hierarchy Process (AHP) in load shedding scheme for electric power system. In International Conference Environment and Electric Engineering, May 2010. 9th International Conference, 365-368.

[7] Kim, D., Braun, J. E., Cliff, E., and Borggaard, J., 2014, Development of control benefit evaluation tool for small commercial buildings, ASHRAE/IBPSA-USA Building Simulation Conference.

[8] Kim, D., Braun, J. E., Cliff, E., and Borggaard, J., 2015, Development, Validation and Application of a Coupled Reduced-order CFD model for Building Control Applications, Building and Environment 93(2), 97-111.

[9] Krarti, M., 2000, Energy audit of building systems: an engineering approach, CRC press, Boca Raton, London, New York.

[10]Lee, K. H., and Braun, J. E., 2008, Model-based demand-limiting control of building thermal mass, Building and Environment 43(10), 1633-1646. 
[11]Lu, N., and Katipamula, S., 2005, Control strategies of thermostatically controlled appliances in a competitive electricity market. In Power Engineering Society General Meeting, June 2005, IEEE 1, 202-207.

[12]Saaty, T. L., 2003, Decision-making with the AHP: Why is the principal eigenvector necessary, European Journal of Operational Research 145(1), 85-91.

[13]Saaty, T.L. and Vargas, L.G., 2012, Models, Methods, Concepts and Applications of the Analytic Hierarchy Process, Vol. 175. Springer Science \& Business Media.

[14] Thumann, A., and Mehta, D. P., 2001, Handbook of Energy Engineering. The Fairmont Press, Inc.

[15]Triantaphyllou, E. and Stuart, H. M., 1995, Using the analytic hierarchy process for decision making in engineering applications: some challenges, International Journal of Industrial Engineering: Applications and Practice 2(1), 35-44.

[16]Yao, Y., Lian, Z., Liu, S., and Hou, Z., 2004, Hourly cooling load prediction by a combined forecasting model based on analytic hierarchy process, International journal of thermal sciences 43(11), 1107-1118.

[17]Wong, J. K. and Li, H., 2008, Application of the analytic hierarchy process in multi-criteria analysis of the selection of intelligent building systems, Building and Environment 43(1), 108-125. 